\title{
Increased A1c Testing among Members of A Large Coordinated Care Organization in Southern California
}

\author{
June 0 Leary ${ }^{1}$, Ning Fu ${ }^{2}$, Janelle Howe ${ }^{3}$, Jeremy Rich ${ }^{4}$ and Glenn Melnick ${ }^{5 *}$ \\ ${ }^{1}$ Independent Contractor/Health Services Researcher Consultant, University of Southern California, USA
}

${ }^{2}$ Post-doctoral Fellow, University of Southern California, USA

${ }^{3}$ Senior Director, Health Enhancement, DaVita HealthCare Partners Medical Group, USA

${ }^{4}$ Director, HealthCare Partners Institute for Applied Research and Education, USA

${ }^{5}$ Blue Cross of California Chair in Health Care Finance, University of Southern California, USA

Received: 酸 April 23, 2018; Published: 些 May 16, 2018

*Corresponding author: Glenn Melnick, Blue Cross of California Chair in Health Care Finance, Sol Price School of Public Policy, University of Southern California, Gateway 101P, Los Angeles, CA, USA.

\begin{abstract}
DaVita HealthCare Partners Medical Group (DHCP), a large coordinated care organization, implemented a population health program to expand the number of southern California members who receive an $\mathrm{A} 1 \mathrm{C}$ test. The $\mathrm{A} 1 \mathrm{C}$ test is used to diagnose prediabetes and diabetes, and to monitor blood glucose control in current diabetic patients. Prediabetes occurs when blood glucose levels are elevated, but not yet high enough to be considered diabetes and it places individuals at higher risk for developing diabetes. Diabetes is a chronic illness and serious complications such as kidney disease, loss of eyesight and amputation can occur when blood glucose is uncontrolled. A1C testing is key not only to the diagnosis and management of diabetes, but also to identification of prediabetes to allow early intervention to delay or stop the transition to diabetes. This Mini Review reports on DHCP's successful A1c testing expansion, which led to over 50,000 members on average receiving an A1c test for the first time each year of the 2007-2016 study period.
\end{abstract}

Keywords: A1C test; Diabetes; Prediabetes; Population health

\section{Introduction}

The Centers for Disease Control and Prevention (CDC) estimate that $9.4 \%$ (30.3 million) of the US population has diabetes, with $24 \%$ (7.2 million) of these individuals undiagnosed [1]. Diabetes and the increase in prevalence of this condition is not just a problem in the US, but worldwide [2]. Diabetes is associated with a variety of health complications (e.g., eye disease, kidney disease, amputations) and in the US average medical expenditures for persons with diabetes is about 2.3 times higher than for persons without diabetes $[3,4]$. Yet, effective self management programs that involve a combination of diet, exercise and possibly medication, can help patients control their prediabetes and diabetes. The US Diabetes Prevention Program indicated that lifestyle changes could reduce the incidence of type 2 diabetes by $58 \%$ over three years [5].

Blood glucose measurements are integral to the diagnosis of diabetes, its management and more recently identification of prediabetes. Prediabetes is a high risk state for developing diabetes, where blood glucose is elevated above normal levels but not yet high enough to be considered diabetes. In the case of the $\mathrm{A} 1 \mathrm{C}$ test, categories include $<5.7 \%$ (normal), 5.7\%-6.4\% (prediabetes) and $\geq 6.5 \%$ (diabetes) [3]. The A1C test is used by diabetic patients and their physicians to monitor blood glucose. Regular measurement of A1C levels enables patients with diabetes and their physicians to know whether patients are reaching their $\mathrm{A} 1 \mathrm{C}$ goals in order to minimize the adverse health outcomes associated with uncontrolled diabetes. The A1C test has the advantage of requiring no preparation and it is not sensitive to the time of day, unlike other blood glucose tests. Consequently, many providers are hopeful that the ease of the $\mathrm{A} 1 \mathrm{C}$ test will decrease the number of undiagnosed diabetics as well as allow for identification of patients with prediabetes and therefore earlier intervention and prevention of diabetes [6]. 


\section{Case Study Site, Study Goals and Results}

Table 1: Average Number of A1c Tests per Member per Year: 2007-2016.

\begin{tabular}{|c|c|c|c|}
\hline Year(s) & $\begin{array}{c}\text { A. Total A1c } \\
\text { Tests }\end{array}$ & $\begin{array}{c}\text { B. Total } \\
\text { Members } \\
\text { Tested }\end{array}$ & $\begin{array}{c}\text { Average } \\
\text { Number of } \\
\text { A1c Tests per } \\
\text { Member (A/B) }\end{array}$ \\
\hline 2007 & 81,864 & 49,314 & 1.66 \\
\hline 2008 & 100,558 & 59,119 & 1.70 \\
\hline 2009 & 144,773 & 86,203 & 1.68 \\
\hline 2010 & 192,306 & 112,950 & 1.70 \\
\hline 2011 & 241,623 & 137,345 & 1.76 \\
\hline 2012 & 256,152 & 152,848 & 1.68 \\
\hline 2013 & 293,108 & 179,044 & 1.64 \\
\hline 2014 & 362,739 & 201,407 & 1.80 \\
\hline 2015 & 509,067 & 224,778 & 2.26 \\
\hline 2016 & 414,726 & 229,673 & 1.81 \\
\hline $2007-2016$ & $2,596,916$ & $1,432,681$ & 1.81 \\
\hline
\end{tabular}

Table 2: Number of Newly Tested Members and Members with Repeat A1c Testing: 2007-2016.

\begin{tabular}{|c|c|c|}
\hline Year & $\begin{array}{c}\text { Members Tested in } \\
\text { this Year for the First } \\
\text { Time }\end{array}$ & $\begin{array}{c}\text { Members Tested in Previous } \\
\text { Years and Tested Again in } \\
\text { this Year }\end{array}$ \\
\hline 2007 & 49,314 & not applicable \\
\hline 2008 & 29,559 & 29,560 \\
\hline 2009 & 46,836 & 39,367 \\
\hline 2010 & 49,533 & 63,417 \\
\hline 2011 & 52,831 & 84,514 \\
\hline 2012 & 51,798 & 101,050 \\
\hline 2013 & 65,641 & 113,403 \\
\hline 2014 & 68,654 & 132,753 \\
\hline 2015 & 71,710 & 153,068 \\
\hline 2016 & 61,684 & 167,989 \\
\hline
\end{tabular}

The site for this study is a large coordinated care organization, DaVita HealthCare Partners, a DaVita Medical Group (DHCP), which serves over half a million members in the greater Los Angeles, California region. DHCP sought to increase A1C testing among its members to help control diabetes and prediabetes and implemented a multifaceted approach, involving both providers and patients over several years [7,8]. This article analyzes the experience of their program to expand $\mathrm{A} 1 \mathrm{C}$ testing as a first step to broader population health management of their membership. We analyze data including the total number of A1C tests and the total members tested over the 10-year period 2007 through 2016. Our calculations focus on the average number of A1C tests per member per year and the number of members newly tested each year of the study period. These results are shown in Tables $1 \& 2$.

\section{Discussion}

This analysis shows that a multifaceted approach to increasing A1C testing among all members of a large coordinated care organization is possible, but particularly members who have never been tested as DHCP members, or not recently. Increases in A1C testing from current levels will be necessary to prevent future cases of diabetes as well as improve blood glucose control. Population health management in the US and other countries can increase testing levels. Tailoring the message according to the characteristics of the target population of patients and providers will undoubtedly be necessary. For DHCP future outreach and embedded research will focus on subpopulations and how best to target A1C testing to identify patients with prediabetes or undiagnosed or uncontrolled diabetes. Only with testing can providers work with patients to help them control their blood sugar levels and possibly avoid a future diabetes diagnosis or poor outcomes such as vision loss and nerve damage.

\section{References}

1. (2017) Centers for Disease Control and Prevention. National Diabetes Statistics Report, Atlanta, GA: Centers for Disease Control and Prevention, US Department of Health and Human Services.

2. (2017) World Health Organization. Fact Sheet: Diabetes.

3. (2017) American Diabetes Association. Standards of Medical Care in Diabetes-2017. Diabetes Care 40(Suppl 1): S6-S10.

4. (2013) American Diabetes Association. Economic Costs of Diabetes in the U.S. in 2012. Diabetes Care 36(4): 1033-1046.

5. Knowler WC, Fowler SE, Hamman RF, Christophi CA, Hoffman HJ, et al. (2009) Diabetes Prevention Program Research Group. 10-year followup of diabetes incidence and weight loss in the Diabetes Prevention Program Outcomes Study. Lancet 374(9702): 1677-1686.

6. (2018) National Institute of Diabetes and Digestive and Kidney Diseases. The A1C Test \& Diabetes.

7. Melnick G, O Leary J, Fu N, Howe J, J Rich (2017) Managing Population Health: Expanding Hemoglobin A1c Testing-The First Step in Controlling Diabetes and prediabetes. Abstracts from the $24^{\text {th }}$ Annual Health Care Systems Research Network Conference, April 11-13, 2018, Minneapolis, Minnesota. J Patient Cent Res Rev 5: 56-131.

8. Chuang C, Melnick G (2018) Expanding A1c Testing to Help Control Diabetes and Prediabetes. The Journal of America's Physician Groups 12(1): 48-49. 


\section{CC (P) This work is licensed under Creative}

To Submit Your Article Click Here : Submit Article

DOI: 10.32474/RRHOAJ.2018.01.000125

Research and Reviews on
Healthcare: Open Access Journal
Assets of Publishing with us
- Global archiving of articles
- Immediate, unrestricted online access
Rigorous Peer Review Process
- Authors Retain Copyrights

